\title{
INVERSE PROBLEMS FOR STURM-LIOUVILLE OPERATORS ON GRAPHS WITH A CYCLE
}

\author{
VJACHESLAV ANATOLJEVICH YURKO
}

\begin{abstract}
An inverse spectral problem is studied for second-order differential operators on graphs with a cycle and with standard matching conditions in the internal vertex. A uniqueness theorem is proved, and a constructive procedure for the solution is provided.
\end{abstract}

Mathematics subject classification (2000): 34A55, 34B24, 47E05.

Keywords and phrases: Sturm-Liouville operators, graphs with a cycle, standard matching condititons, inverse spectral problems.

\section{REFERENCES}

[1] R. Beals, P. Deift And C. TomeI, Direct and Inverse Scattering on the Line, Math. Surveys and Monographs, v. 28. Amer. Math. Soc. Providence: RI, 1988.

[2] M. I. BELISHEV, Boundary spectral inverse problem on a class of graphs (trees) by the BC method, Inverse Problems 20 (2004), 647-672.

[3] R. Bellmann And K. Cooke, Differential-difference Equations, Academic Press, New York, 1963.

[4] B. M. BRown AND R. WeIKARD, A Borg-Levinson theorem for trees, Proc. R. Soc. Lond. Ser. A Math. Phys. Eng. Sci. 461, no. 2062 (2005), 3231-3243.

[5] K. Chadan, D. COlton, L. PAivarinta AND W. Rundell, An introduction to inverse scattering and inverse spectral problems. SIAM Monographs on Mathematical Modeling and Computation, SIAM, Philadelphia, PA, 1997.

[6] J. B. ConwaY, Functions of One Complex Variable, 2nd ed., vol. I, Springer-Verlag, New York, 1995.

[7] G. FreILING AND V. A. YURKO, Inverse Sturm-Liouville Problems and their Applications, NOVA Science Publishers, New York, 2001.

[8] G. FREILING AND V. A. YURKO, Inverse spectral problems for Sturm-Liouville operators on noncompact trees, Results in Math. 50 (2007), 195-212.

[9] B. M. Levitan, Inverse Sturm-Liouville Problems, Nauka, Moscow, 1984 (Russian); English transl., VNU Sci. Press, Utrecht, 1987.

[10] V. A. MarchenKo, Sturm-Liouville Operators and their Applications, Naukova Dumka, Kiev, 1977 (Russian); English transl., Birkhauser, 1986.

[11] V. A. MARChENKO AND I. V. OSTROVSKII, A characterization of the spectrum of the Hill operator, Mat. Sbornik 97 (1975), 540-606 (Russian); English transl. in Math. USSR Sbornik 26 (1975), 4, 493-554.

[12] M. A. NAIMARK, Linear Differential Operators, 2nd ed., Nauka, Moscow, 1969; English transl. of 1st ed., Parts I,II, Ungar, New York, 1967, 1968.

[13] YU. POKORNYI AND A. BOROVSKIKH, Differential equations on networks (geometric graphs), J. Math. Sci. (N.Y.) 119, no. 6 (2004), 691-718.

[14] YU. POKORNYI AND V. PRYADIEV, The qualitative Sturm-Liouville theory on spatial networks, J. Math. Sci. (N.Y.) 119 (2004), no. 6, 788-835.

[15] J. Pöschel AND E. Trubowitz, Inverse Spectral Theory, New York, Academic Press, 1987.

[16] I. V. StANKEVICH, An inverse problem of spectral analysis for Hill's equations, Doklady Akad. Nauk SSSR 192, no. 1 (1970), 34-37 (Russian).

[17] V. A. YURKO, Method of Spectral Mappings in the Inverse Problem Theory, Inverse and Ill-posed Problems Series, VSP, Utrecht, 2002. 
[18] V. A. YURKo, Inverse Spectral Problems for Differential Operators and their Applications, Gordon and Breach, Amsterdam, 2000.

[19] V. A. YURKO, Inverse spectral problems for Sturm-Liouville operators on graphs, Inverse Problems 21 (2005), 1075-1086.

[20] V. A. YURKO, Inverse problems for arbitrary order differential operators on trees, Matemat. Zametki 83, no. 1 (2008), 139-152 (Russian); English transl. in Math. Notes 83, no. 1 (2008), 125-137. 